\title{
SUSTAINABLE TOURISM DEVELOPMENT STRATEGIES AND PRACTICES OF WORLD HERITAGE SITES IN CHINA: A CASE STUDY OF MT. HUANGSHAN
}

\author{
HONGBING ZHU, JUNXIANG ZHANG, XIANGYANG YU \& SHANFENG HU \\ School of Tourism, Huangshan University, China.
}

\begin{abstract}
World Heritage Sites (WHS) represent the most important natural and cultural heritage places in the world, which are also the most popular tourism destinations. This study focuses on the dynamic relationship between sustainable development and heritage tourism in the context of WHS, with special attention to the sustainable tourism development strategies and practices of the mixed WHS Mt. Huangshan in the developing country, China. This study finds that there exists a conflict between WHS sustainable development and heritage tourism development. Seven themes related to sustainable tourism development practices and strategies of Mt. Huangshan were found based on the content analysis, which also reflect the sustainable development principles in terms of environmental sustainability, inclusive social development, and economic development. Future research agendas, for example, the value-based management approach and stakeholders coordination are also proposed. This study contributes to the existing knowledge in both theory and practice of sustainable tourism development of WHS, especially in developing country.

Keywords: developing country, Mt. Huangshan, sustainable development, sustainable tourism, World Heritage Sites.
\end{abstract}

\section{INTRODUCTION}

World Heritage Sites (hereafter WHS) represent the most important natural and cultural heritage places in the world, which are also the most visited tourist destinations [1]. By July 2018, 1092 sites were listed as WHS, including 845 cultural sites, 209 natural sites, and 35 mixed properties. However, the rapidly growing number of tourists to the WHS also generates significant challenges on how to protect the Outstanding Universal Values (OUV) of WHS while simultaneously meeting the public's increasing demand for access to the WHS. In fact, the issues of WHS sustainable development have also been explicitly listed on the top priorities by the UN on its 17 Sustainable Development Goals, which is described in the sub-goal 11.4 as strengthening 'the efforts for the protection and safeguarding of the world's natural and cultural heritage.' This means that the WHS sustainable development has been put on the mainstream sustainable development debate issues.

Meanwhile, China has become the second most important country in terms of the number of WHS. However, the research on sustainable tourism development of world heritage in China is still a recent new phenomenon. Thus there is an urgent need to conduct more detailed empirical research at WHS in China to understand the governance and protection strategies and practices, which finally contribute to the theory and practical development of WHS [2]. A review of the heritage sustainable tourism literature indicates that most studies focus on the conceptual and theoretical relationship between sustainable development and heritage tourism, which lacks practical insights into the sustainable tourism management and planning, especially in the context of WHS. Therefore, based on the above discussion, this study aims to explore the practical issues of sustainable tourism development in the context of WHS in China, and by providing a case study from one famous mixed WHS, Mt. Huangshan to illustrate its successful practices of sustainable development and management strategies. 
This study is divided into five sections as follows. It starts with the brief introduction of World Heritage and discusses its relationship with tourism. Section 2 explores the theories related to sustainable development and World Heritage sustainable tourism in current literature, and also the research method and research context used in this study. Section 3 investigates the WHS sustainable tourism development in China. Section 4 identifies the themes of sustainable tourism development practices and strategies of Mt. Huangshan based on the content analysis in terms of environmental sustainability, inclusive social development, and inclusive economic development. Conclusions and future research directions are summarized in the final section.

\section{SUSTAINABALE TOURISM DEVELOPMENTS OF WORLD HEIRTAGE SITES IN CHINA}

\subsection{Sustainable tourism of WHS}

Since the adoption of the Convention concerning the protection of the World Cultural and Natural Heritage (hereafter Convention) by the United Nations Educational, Scientific and Cultural Organization (UNESCO) in 1972, the WHS have continually evolved and are growing steadily. The Convention encourages the identification, protection, and sustainable development of cultural and natural heritage around the world which has outstanding value to humanity. The World Heritage brand has the potential to be used to promote sustainability [3]. First, by identifying, protecting, and transmitting the cultural and natural heritage properties of OUV for future generations, the WHS, in itself, contribute significantly to sustainable development. In addition, WHS brand conform to a UNESCO standard certification of place quality. These WHS are recognized as iconic and most valued destinations. This brand has a greater tourist enhancing effect, especially in attracting the international tourists [4]. Second, WHS provide important benefits, including revenues and jobs from tourism, water supply and food security. The economic value of the WHS to users or tourists exceeds its monetary benefits [5]. Thus they contribute to the well-being of local, national, and even global communities. There also exist many critical issues challenging the sustainable development of WHS. For example, in one study by King and Halpenny, it was found that world heritage brand symbol has been poorly used by the management agencies which impede visitors and communities to recognize its importance [3]. Educating and raising people's awareness of WHS are fundamental to achieve sustainable development [6]. However, heritage was long absent from the mainstream sustainable development debate despite its crucial importance to the sustainability. This study adopts a sustainable development perspective within the WHS to investigate sustainable tourism development practices at one WHS in China.

Most models of sustainable development include three broad principles, namely environmental sustainability, inclusive economic sustainability, and the inclusive social development [7]. These three principles can also be used in the WHS to guide sustainable tourism development [8]. Sustainable tourism refers to 'tourism that takes full account of its current and future economic, social and environmental impacts, addressing the needs of visitors, the industry, the environment and host communities' (P. 12) [9]. Environmental sustainability refers to protecting the biodiversity, geodiversity, and the ecosystem integrity, which help to conserve natural heritage and maintain essential ecological processes. Economic sustainability aims to provide economic benefits for all the stakeholders, and bring stable employment and income for the local communities in order to alleviate poverty. Inclusive social sustainability assumes economic growth constrained by the requirements for equity, empowerment, 
cultural identity and institutional stability. The critical issue for sustainable tourism is to balance the environmental, economic and inclusive social dimensions of sustainable development over time [10]-[11].

\subsection{Sustainable tourism at WHS in China}

China has many places that have been placed on the list of WHS due to its rich culture, long history, and varied natural resources. Since China joined the Convention in 1985, 53 sites (including 36 cultural heritage sites, 13 natural heritage sites, and 4 mixed heritage sites) have been designated as WHS by the UNESCO with it becoming the second most significant country in terms of volume of WHS after Italy in the World. As shown in Table 1, the number of WHS has increased significantly in the past 30 years from 6 in 1987 to 53 in 2018. Over this same period, the ratio of WHS in China to the total number in the world has increased greatly from $2.10 \%$ in 1987 to $4.85 \%$ in 2018 .

The WHS brand has a strong effect on enhancing tourist interest, especially when attracting the international tourists in China [12]. It can bring many potential benefits for the tourism destination, like increasing national pride and prestige, additional funding, adding value as a high quality brand for tourism development [13]. Tourism can also play a positive role in protecting the WHS through generating revenue, educating tourists, and engaging local communities. However, on the other hand, the growing number of tourists and ill-planned and mismanaged tourism activities can also generate serious damaging effects on the cultural and physical properties of WHS and degrade the quality of the visitor experience. Environmental impacts of tourism are common across China's WHS [13]. For example, the WHS of Zhangjiajie in China has been warned twice in 2002 and 2012, respectively, due to its improper management of the site. An example of this is the construction of a cable car inside the site which destroyed the ecosystem of the heritage site. Furthermore, according to one study, there are three main threat factors that affect the heritage site development in China,

Table 1: Total number of WHS inscribed in the world and China.

\begin{tabular}{ccccccc}
\hline Year & $\begin{array}{c}\text { Total No. } \\
\text { in World }\end{array}$ & $\begin{array}{c}\text { Total No. } \\
\text { in China }\end{array}$ & $\begin{array}{c}\text { Heritages } \\
\text { in China }\end{array}$ & $\begin{array}{c}\text { Cultural } \\
\text { Heritages } \\
\text { in China }\end{array}$ & $\begin{array}{c}\text { Mixed } \\
\text { Heritages } \\
\text { in China }\end{array}$ & $\begin{array}{c}\text { Ratio } \\
\text { (China/ } \\
\text { World) } \\
(\%)\end{array}$ \\
\hline 1987 & 285 & 6 & 0 & 5 & 1 & 2.10 \\
1990 & 335 & 7 & 0 & 5 & 2 & 2.09 \\
1995 & 468 & 14 & 3 & 9 & 2 & 2.99 \\
2000 & 690 & 29 & 3 & 22 & 4 & 4.20 \\
2005 & 812 & 35 & 4 & 27 & 4 & 4.31 \\
2010 & 890 & 40 & 8 & 28 & 4 & 4.49 \\
2015 & 1031 & 48 & 10 & 34 & 4 & 4.66 \\
2016 & 1052 & 50 & 11 & 35 & 4 & 4.75 \\
2018 & 1092 & 53 & 13 & 36 & 4 & 4.85 \\
\hline
\end{tabular}

Source: United Nations Educational, Scientific and Cultural Organization (UNESCO). 
namely the lack of financial support, local economy development polices, and the population pressure at present [13]. Another important challenge for tourism management at WHS is how to respond to the increasing demand for access to these sites, while protecting the Outstanding Universal Values for which they were inscribed on the World Heritage List. WHS are often the most popular visitor attractions for a destination. However, the excessive visitor numbers often lead to congestion especially in the peak tourism season period, which may pose major threats to the heritage values of the place and also degrade the quality of the visitor experience. Congestion can also result in operational inefficiencies, increased business costs, and the disorderly competition among the heritage sites.

In fact, the primary goal in listing the WHS is to protect the significant tangible and intangible natural and cultural properties, which are considered to be of OUV to human civilization [14]. However, paradoxically, these heritage sites have been developed as the main tourism resources for economic development in many areas in China. Fortunately, in recent years, the Chinese government has made great efforts to improve the sustainable development of WHS. For instance, the second Saturday of June has been established as the 'Cultural and Natural Heritage Day' from 2017 by the Chinese government. It aims to arouse and enhance the consciousness of the whole society for care, support, and participation in heritage protection.

\section{RESEARCH METHOD AND RESEARCH CONTEXT}

\subsection{Research method}

This study adopts the case study methodology with the document analysis. A case study provides tools for researchers to study complex issues in real world settings. It can lead to comprehensive in-depth understanding of sustainable tourism development practices within the research context. Secondary data were used in this study. The main secondary data was obtained through an extensive documentary search. Chapman and McNeill [15] have identified six categories of secondary documents, including literature, public official records, personal documents, biography, and autobiography, print and visual media, and historical documents. It is usual for multiple sources of evidence to be used in case study [16]. As such, in this research, the researchers obtained and reviewed the public documents, tourism planning reports, journal articles and statistic data in English and Chinese languages from the government website (e.g. http://www.chinahuangshan.gov.cn), UNWTO websites, Google Scholars, and so on.

The authors have been working in the city of Huangshan for many years and has participated several projects related to the tourism development of Mt. Huangshan and consequently are able to investigate the case from a dynamic and holistic view. This research uses the deductive content analysis approach based on a structured predetermined codebook as a reference to guide for the data analysis. Content analysis is a research technique by interpreting and coding textual material. In this study, the research questions and objectives were used as a guide for grouping and analysing the data. All of the researchers are very familiar with the sustainable development practices of Mt. Huangshan. The research team met together to examine all the documents to determine the main categories to be used when coding the data. The authors organize and categorize the data according to the research objectives and also the sustainable development principles. Finally, a consensus was reached among the seven themes related to the sustainable management strategies and practices of the world heritage destination, Mt. Huangshan. 


\subsection{Research context - world cultural and natural heritage site of Mt. Huangshan}

This paper chose Mt. Huangshan as the case research context. The rationale for the selection of this place as a study area is based on the following three perspectives.

First, the site must have been listed as the WHS. In the scope of the World Heritage in China, Mt. Huangshan has a strong representation. Early in 1990, Mt. Huangshan was listed as a World Cultural and Natural Heritage Site by UNESCO based on the OUV criteria (ii), (vii), and (x). Mt. Huangshan, also called as Yellow Mountain, lies in the city of Huangshan, Anhui province and about $500 \mathrm{~km}$ southwest of Shanghai. It is known as 'the loveliest mountain of China', which includes massive uniquely shaped rocks, granite peaks, waterfalls, and hot springs, formed by its complex geological history.

Second, Mt. Huangshan has become one of the most important and popular tourism destinations in China. The purpose of this study is to investigate the sustainable tourism development practices in WHS. Therefore, it should be a popular tourist attraction, appealing to a significant number of tourists. In 1990 the site only received 0.7 million tourists, while the number had significantly increased to 3.4 million tourists in 2018 , and the tourism revenue increases to 3.0 billion RMB in 2018 (see Fig. 1).

Third, Mt. Huangshan follows good practices in sustainable tourism management. In recent years, Mt. Huangshan has been given many national and international awards for its sustainable tourism management. For example, Mt. Huangshan has been rated successively as the National Scenic Spot, National Geopark and National Forest Park. In 2007, this mountain was awarded as an AAAAA scenic area by the Chinese National Tourism Administration, which is the highest grade for scenic appraisal standard. In addition, Mt. Huangshan has also won many international prizes, thus reflecting its success in heritage sustainable management. In 2004, it was listed as Huangshan Geopark by UNESCO. In 2008, International Conference on Sustainable Tourism Management at WHS was held at Mt. Huangshan by UNWTO and UNESCO, and concluded with the Huangshan Declaration. Since then, the first Observatory on Sustainable Tourism Development at WHS - Mt. Huangshan was set up. It was awarded the Destination Stewardship Award by World Travel \& Tourism Council

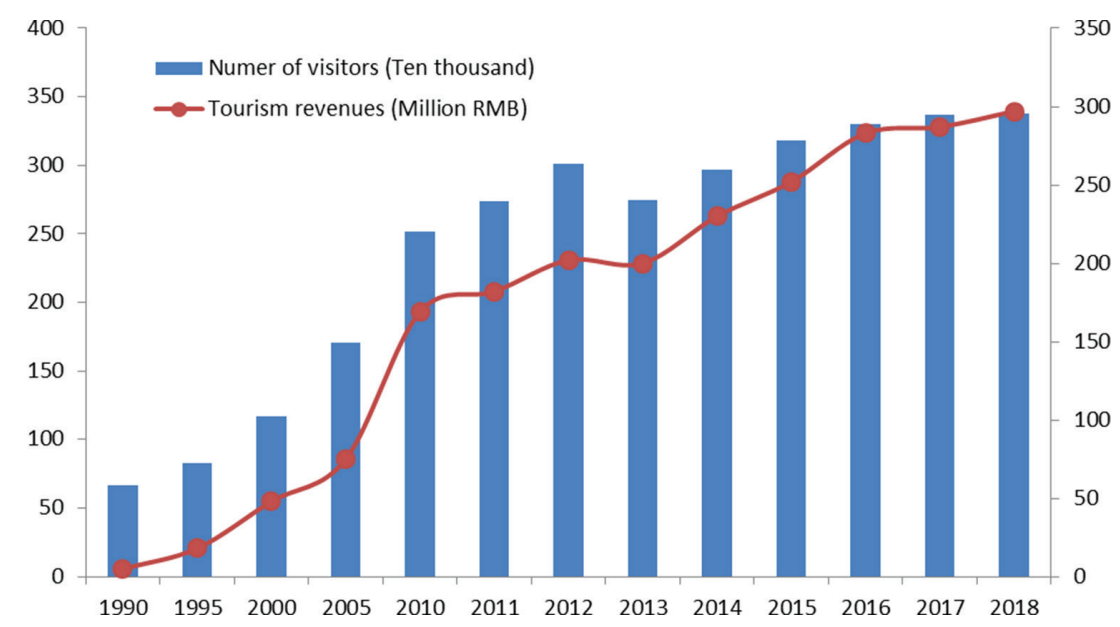

Figure 1: Tourist Arrivals and Revenue of Mt. Huangshan (1990--2018)

Source: Anhui Annual Statistic Report 
(WTTC), China Responsible Tourism Award by Pacific Asia Travel Association (PATA), and IUCN Green List of Protected Areas (IUCN, 2014). Therefore, these awards reflect the heritage's success in the dual pursuit of heritage conservation and economic development, which in turn brings much fame and branding effect to its tourism marketing.

\section{THE SUSTAINABLE TOURISM DEVELOPMENT PRACTICES OF THE WHS, MT. HUANGSHAN}

This study identifies seven themes related to sustainable tourism development based on content analysis of Mt. Huangshan. The seven themes also reflect the sustainable development practices and strategies of Mt. Huangshan in three dimensions in terms of environmental sustainability, inclusive social development, and economic development [17].

Table 2: Sustainability related regulations and policies of Mt. Huangshan.

\begin{tabular}{lc}
\hline Name of Protection Law, Regulations, and Measures Documents & Year \\
\hline Administration Law Regulations of the Mt. Huangshan Scenic Spots & 1989
\end{tabular}

Measures for the Administration of Quarantine and Inspection of Forest Plants of Mt. Huangshan

Regulations on the Protection of Cultural Resources of Mt. Huangshan

Emergency Plan for Unexpected Geological Disasters of Mt. Huangshan

Measures for the Implementation of the "One Vote Veto" on Ecological

Construction and Environmental Protection of Mt. Huangshan

Measures for the Administration of Special Landscape Planning and

Administration of Mt. Huangshan

2014

Ecological Environmental Protection Implementation Strategy of Mt. Huangshan

Measures for Reward and Punishment of Forest Fire Prevention of

Mt. Huangshan

Safety Production and Management Responsibility System of Mt. Huangshan

Measures for the Tourism Management in Tiandu Peak and Lotus Peak of

Mt. Huangshan

Measures on Further Strengthening the Environmental Protection of Mt. Huangshan

Note: This table is the author's own synthesis and only list some main regulations, policies concerning the sustainable development of Mt. Huangshan.

Source: http://www.chinahuangshan.gov.cn 


\subsection{Development of sustainable regulations and policies}

Mt. Huangshan set up a number of policies and regulations for its protection and conservation. These regulations and policies guide sustainable tourism development in Mt. Huangshan from the top level in many areas, which include ecological construction, environmental protection, safety management, and cultural resource conservation (see Table 2). In addition, the authorities continue to update these policies and regulations according to its tourism development and heritage protection status.

\subsection{Adoption of innovative sustainable development practices}

Mt. Huangshan has developed a number of innovative ways to contribute to the conservation of its outstanding heritage value. For instance, since 1987 Mt. Huangshan has implemented the rotation management system for the most visited mountain peaks (e.g. Lotus Peak, Tiandu Peak). This means tourists can visit one peak at one time while the other peak is closed for three to five years for ecology recovery. Over the 30 years' rotation management process, the forest vegetation restores well. The forest coverage in Mt. Huangshan has increased from $56 \%$ in 1970 s to $84.7 \%$ in 1990 , and the vegetation coverage rate reached $93.6 \%$ in 2018 . In addition, the authorities have established the 'Forest Health Chief Expert', 'Classified Protection', and 'One Tree One Policy' systems to protect the ancient and famous pines on the mountain. For example, the authorities have implemented the automatic climate monitor for the Welcoming Pine, and also arranged special 24 hour personnel care of this tree per day.

\subsection{Improvement of visitor experience quality}

In order to improve the visitor experience quality and finally contribute to environmental sustainability, Mt. Huangshan has implemented capacity management approach at the Tiandu Peak and Lotus Peak. On fine weather day, the maximum amount of tourists is 3000 per day, while the number declines to 2000 on rainy weather. In addition, Mt. Huangshan has also established the Mt. Huangshan Scenic Spot Emergency Rescue Group, and set up disaster management systems which use digital means to ensure tourists' safety.

\subsection{Cooperation between national and international organizations}

Mt. Huangshan not only cooperated with national agencies and organizations, it also actively joined many international tourism and heritage organizations. In 2015, as one of the initiate units, Mt. Huangshan cooperated with another 22 mountain sites to establish the China Mountain Tourism Alliance in the city of Huangshan. This is a non-profit social organization which aims to promote resources and environmental protection, strengthen management and marketing cooperation, and finally lead to mountain tourism sustainable development. Furthermore, in recent years Mt. Huangshan has also joined and cooperated with many international organizations (e.g. UNWTO, UNESCO, IUCN, and WTTC) for the purpose of organizing conferences or develop standards on sustainable tourism development. Early in 2005, Mt. Huangshan obtained the environmental management certification of ISO14001. Furthermore, in 2008, the International Conference on Sustainable Tourism Management at WHS was held in Mt. Huangshan by UNWTO and UNESCO, and concluded with the Huangshan Declaration. In the same year, the first UNWTO Observatory on Sustainable 
Tourism Development was set up at the WHS, Mt. Huangshan. In 2010, Mt. Huangshan joined the Global Sustainable Tourism Council (GSTC), and Mt. Huangshan helped to formulate the Global Sustainable Tourism Criteria for Destination and revise the Global Sustainable Tourism Guidelines for Hotels and Tour Operators. In 2013, Sustainable Travel International (STI) invited Mt. Huangshan to co-found Sustainable Destination Leadership Network so as to promote sustainable development experience. In fact, on the one hand, such cooperation has enhanced the sustainable tourism development of Mt. Huangshan; on the other hand, it has also passed on the Mt. Huangshan's heritage and tourism sustainable development experience to other WHS.

\subsection{Maximizing the economic impacts of local economic development}

WHS can offer great potential to alleviate poverty and enhance sustainable livelihoods of local communities. As a driving engine for regional economy development, Mt. Huangshan Tourism Group (HTG) has become the biggest enterprise in Huangshan City in terms of enhancing livelihoods, income, and employment for the local communities. During the 12th Five-Year period (2010-2015), Mt. Huangshan received about 15 million tourists, and achieved operating income of about 11 billion yuan (RMB), and paid tax of 1.2 billion yuan. According to the 13th Five-Year planning report, Mt. Huangshan will receive around18 million tourists in the next five years (2016-2020), the operation income will reach at 31 billion yuan, and the tax paid will be 3 billion yuan with an average annual growth of $30.52 \%$.

\subsection{Enhancing local communities' quality of life and well-being}

Mt. Huangshan respects and involves the local communities in the tourism development process which contribute to the inclusive social sustainability. Mt. Huangshan has opened the south gate in Tangkou Town, which increases the tangible and intangible benefits to the local communities, for example, increasing the number of tourists, bringing more income to the local people, improving place reputation, and promoting local culture [18]. In addition, in order to enhance the local communities' participation and support for the protection of WHS, Mt. Huangshan initiated a free ticket policy for the local community during some special period of the year.

4.7 Exploration of new modes to improve public heritage awareness

Mt. Huangshan continues to explore new heritage education modes to improve people's heritage awareness, especially among young students. For example, the authorities initiated the 'World Heritage Walk into the University' campaign to carry out the heritage propaganda through a variety of activities such as 'Famous Experts Explain Mt. Huangshan' and 'Biological Mystery Exploration of Mt. Huangshan'. Also, the authorities gave a special discount for the student tour in the form of an entry ticket and accommodation.

\section{DISUCSSIONS AND CONCLUSIONS}

This research analyses the sustainable tourism development strategies and practices of the WHS, Mt. Huangshan in China. There are several important findings related to this topic. Firstly, the interaction between WHS and tourism development has been both dynamic and closely related. On the one hand, WHS are often major tourist attractions for the tourism sector; however on the other hand, well-managed tourism activities can generate funds for conservation of WHS, while also contributing to the socio-economic development of local destinations and improving the quality of life for local residents. Secondly, the heritage sites should know 
how to effectively engage with the local communities for sustainable tourism development. Local residents are the heart of sustainable tourism, thus the heritage and tourism sectors should create opportunities to listen to the local community in order to ensure the host community is given a high important status in the destination strategy. Thirdly, communicating heritage values to the tourists is another critical aspect of development of sustainable tourism. Well-informed visitors are at the very centre of all sustainable tourism activities. Therefore, the tourism activities at the heritage sites should aim to enhance the visitor's understanding of the heritage values and emotional attachment through proper interpretation. With good interpretation, tourists are more likely to appreciate the distinctive features of the heritage site, and further become the advocator for heritage conservation. In essence, it is the responsibility of the heritage site to communicate the most valuable aspects of the place to tourists. Fourthly, sustainable development at heritage sites require more rigorous, effective, cooperative coordination between site management and all relevant public agencies and private enterprises to minimise the adverse effects arising from the ill-managed tourism activities. Without good management and coordination among the different stakeholders, it is impossible to make tourism development sustainable and economically effective. Therefore, the tourism and heritage sectors should combine to build a positive, dynamic, and responsive relationship between each other.

In future, Mt. Huangshan, and also other WHS in the world should take more sustainable heritage tourism practices, including the multiple stakeholders' cooperation and a comprehensive, long-term, and holistic tourism planning process [19]. On the one hand, the bottom-up process should be established and more stakeholders should be empowered and incorporated into the sustainable planning and management process of WHS. Just as Huangshan Declaration described 'the conservation and sustainable development of World Heritage sites should address changes in human-environment relationships, not only within the sites themselves but also in the broader regional ecosystems and territories in which they are embedded' (Huangshan Declaration, 2014). On the other hand, a value-based management approach should be used by the management agencies to ensure the authenticity and integrity of WHS. This value-based management approach adopts the philosophy that the values of the site are important not only to a group of heritage experts and official people, but also to a variety of stakeholders, including the local residents and visitors. Furthermore, UNESCO has recently published a series of 'How To' guides, namely UNESCO World Heritage Sustainable Tourism Toolkit, which contains 10 different guide topics in order to help the different stakeholders in the World Heritage destination to implement best practice approaches to sustainable tourism development.

To conclude, through the content analysis of the sustainable development practices and strategies of the WHS, Mt. Huangshan, this study contributes to the existing knowledge in both theory and practice of sustainable tourism development of WHS over the long term, especially in developing country.

\section{ACKNOWLDEGMENTS}

This project is financially supported by the National Natural Science Foundation of China (41571140), Anhui Natural Science Key Project (KJ2018ZD040), the Key Discipline Construction Project (zdxk201804), Anhui Outstanding Young Scholar Project (gxyqZD2019067), and the following Anhui Social Science Key Projects (SK2015A526; SK2016A0893; AHSKZ2015D15).

\section{REFERENCES}

[1] UNWTO, Sustainable Tourism Management at World Heritage Sites - Enhancing Inter-agency and Stakeholder Coordination for Joint Action, Madrid: World Tourism Organization, 2009. 
[2] Su, M.M. \& Wall, G., Chinese research on world heritage tourism. Asia Pacific Journal of Tourism Research, 16(1), pp. 75-88,2011. https://doi.org/10.1080/10941665.2011.539392

[3] King, L.M. \& Halpenny, E.A., Communicating the world heritage brand: Visitor awareness of UNESCO's World Heritage symbol and the implications for sites, stakeholders and sustainable management. Journal of Sustainable Tourism, 22(5), pp. 768-786, 2014. https://doi.org/10.1080/09669582.2013.864660

[4] Yang, C.H., Lin, H.L. \& Han, C.C., Analysis of international tourist arrivals in China: The role of World Heritage Sites. Tourism Management, 31(6), pp. 827-837, 2010. https://doi.org/10.1016/j.tourman.2009.08.008

[5] Kim, S.S., Wong, K.K.F. \& Cho, M., Assessing the economic value of a world heritage site and willingness-to-pay determinants: A case of Changdeok Palace. Tourism Management, 28(1), pp. 317-322, 2007. https://doi.org/10.1016/j.tourman.2005.12.024

[6] Drost, A., Developing sustainable tourism for world heritage sites. Annals of Tourism Research, 23(2), pp. 479-484, 1996. https://doi.org/10.1016/0160-7383(96)83345-7

[7] Basiago, A.D., Economic, social, and environmental sustainability in development theory and urban planning practice. The Environmentalist, 19(2), pp. 145-161, 1998. https://doi.org/10.1023/a:1006697118620

[8] Pirlone, F. \& Spadaro, I., Sustainable tourism action plan in the Mediterranean Coastal Areas. International Journal of Sustainable Development and Planning, 12(6), pp. 995-1005, 2017. https://doi.org/10.2495/sdp-v12-n6-995-1005

[9] UNEP. \& UNWTO, Making Tourism More Sustainable - A Guide for Policy Makers. Madrid: UNWTO,2005.

[10] Bramwell, B. \& Lane, B., Sustainable tourism: An evolving global approach. Journal of Sustainable Tourism, 1(1), pp. 1-5,1993. https://doi.org/10.1080/09669589309514792

[11] UNESCO, ICCROM, ICOMOS \& IUCN., Managing Natural World Heritage, Paris: UNESCO World Heritage Centre, 2012.

[12] Leung, Y.F., Environmental impacts of tourism at China's World Heritage sites: Huangshan and Chengde. Tourism Recreation Research, 26(1), pp. 117-122, 2001. https://doi.org/10.1080/02508281.2001.11081186

[13] Li, M., Wu, B. \& Cai, L., Tourism development of world heritage sites in China: A geographic perspective. Tourism Management, 29(2), pp. 308-319, 2008. https://doi. org/10.1016/j.tourman.2007.03.013

[14] UNESCO, Operational guidelines for the implementation of the World Heritage Convention. Online. http://whc.unesco.org/archive/opguide13-en.pdf (accessed 15 June 2017).

[15] Chapman, S. \& McNeill, P., Research Methods, London: Routledge, 2005.

[16] Yin, R.K., Case Study Research: Design and Methods, 4th ed., London: Sage, 2009.

[17] Xu, H., Zhu, D. \& Bao, J., Sustainability and nature-based mass tourism: lessons from China's approach to the Huangshan Scenic Park. Journal of sustainable tourism, 24(2), pp. 182-202, 2016. https://doi.org/10.1080/09669582.2015.1071381

[18] Hu, S., Yu, X. \& Zhu, H., Research on the perception of social and cultural impact from residents around mountain heritage areas - A case study of Huangshan Mountain Scenic Areas. Journal of Hefei University of Techonology (Social Sciences), 27(6), pp. 29-33, 2013. (in Chinese)

[19] Landorf, C., Managing for sustainable tourism: A review of six cultural World Heritage Sites. Journal of Sustainable Tourism, 17(1), pp. 53-70, 2009. https://doi. org/10.1080/09669580802159719 